\title{
Die tödliche Krankheit von Ernst Bumm.
}

Sehr geehrter Herr Kollege!

Gern kommen wir Ihrem Wunsche nach, Ihnen über die tödliche Erkrankung Ernst Bumms Mitteilung zu machen:

Bum m war Ende Noyember nach einem Diätfehler von heftigen Schmerzen in der Lebergegend befallen worden. Der behandelnde Arzt hatte eine Gallenblasenschwellung gefühlt und „Cholezystitis und Colitis" diagnostiziert. Auf Rizinus waren am 2. Tage die Beschwerden geschwunden. Weiterhin gute Erholung; Gewichtszunahme; nur lästige Trockenheit im Munde.

Am 29. XII. 1924 nach reichlichem Mittagessen Mattigkeitsgefühl. Als Abendessen eine geringe Menge gewürzter Speisen. B u m m ging um Mitternacht zu Bett- und las noch bis 2 Uhr. Nach einstündigem Schlafe wachte er mit den gleichen Kolikschmerzen im rechten Oberbauche auf wie vor 6 Wochen. Auf Pantopon Schlaf bis 9 Uhr vormittags. Dann erneuter Anfall; nochmals Pantopon.

Wir wurden zugezogen und fanden gegen $1 / 211$ Uhr Bum kollabiert vor. Doch war der Puls befriedigend. Leib etwas aufgetrieben, gespannt; rechts oben starke Druckempfindlichkeit und Muskelabwehr. Aufstoßen, Erbrechen, Schulterschmerz fehlten. Trockene Zunge, Windverhaltung, völlige Darmruhe.

Vorläufige Diagnose: Gallenblasenkolik (Darmverschluß ?)

Nach Morphiumverabfolgung Ueberführung in die Chirurgische Klinik, woselbst nochmalige gemeinsame Beratung: Besserung des Allgemeinzustandes - auch nach eigener. Empfindung des Kranken, der Schlafbedürfiïs hat -; Rückgang der Bauchdeckenspannung; Leib noch empfindlich, aber eindrückbar; in der Gallenblasengegend keine Anschwellung tasstbar. 
Kurz vor einer dritten gemeinsamen Beratung ( $1 / 25 \mathrm{Uhr}$ ) steht B u m m auf und läßt Urin, der nichts Krankhaftes, auch keinen Gallenfarbstoff enthält. 37,5 Temperatur, 84 Puls. Winde, Darmgeräusche fehlen. Bei tiefem Eindrücken geringe Muskelspannung, besonders rechts oben und unten. Krampfschmerz schwindet auf $1 / 2 \mathrm{mg}$ Atropin; der Leib wird weich und eindrückbar.

Im Laufe des Abends (4. Beratung) zeitweise kurzer Krampfschmerz; aber Oberbauch im Ganzen frei. Allgemeinbefinden gebessert, Darmrohr eingelegt. Dabei geht ein Wind ab. In der Nacht im allgemeinen ruhiger Schlaf. Nach hastigem Teetrinken einmal etwas Erbrechen.

Am 31. XII., früh 9 Uhr; plötzlich erneute heftige Schmerzen im ganzen Leib, besonders in der Magen- und Lebergegend, mit Aufstoßen. Keine Winde, keine Peristaltik. Es kommen starke Spannung und Schmerzen in der linken Unterbauchgegend hinzu. Daher unter der Diagnose: „Perforation mit beginnender Peritonitis (?), I,leus (?)" in Allgemeinnarkose Laparotomie (Jehn) in der Mittellinie:

Ein Stieltupfer holt aus dem kleinen Becken gallig gefärbte Flüssigkeit. Darmschlingen leicht meteoristisch und hyperämisch; eine ins kleine. Becken herabsteigende Schlinge zeigt ikterischen Fibrinbelag (Kultur von Fibrinflocke: Koli). Unter Erweiterung der Schnitte wird tief an der Leberpforte die geschrunıpte, kaum daumengroße Gallenblase freigelegt. An ihrer Spitze fast pfenniggroßes Loch. Man fühlt in ihr 2. Steine; sie wird entfernt. In der Gallenblase zwei kirschgroße Maulbeerpigmentsteine; Wand chronisch entzündet, stellenweise geschwürig. Choledochus frei. Tamponade. Bauchhöhlenspülung. Bauchdeckennaht. (Operationsdauer 3/4 Stunde.)

Der Kranke hat den Eingriff bei gutem Pulse zunächst gut überstanden. Am Spätnachmittage trifft $S$ a uerbruch, der auf sofortige Benachrichtigung über die Erkrankung $\mathrm{Bum} \mathrm{ms}$ eine auswärtige Konsultationsreise abgebrochen hatte, ein. Gemeinsame Beratung: Zustand schwer; aber nicht hoffnungslos.

Am 1. I. schläft der Kranke viel, fühlte sich ziemlich wohl. Aber der Puls geht nach und nach in die Höhe. Abends wird die fortschreitende Peritonitis deutlicher. Ihr erliegt Bum m am 2. I.; abends 8 Uhr 45 Minuten.

Sektion nicht gestattet.

Epikrise: Als wir den Erkrankten das erstemal sahen, dachten wir in erster Linie an "Gallensteinkolik". Indessen war das klinische Bild verschwommen und nicht darum eindeutig. $\mathrm{Ob}$ damals schon der Durchbruch im Gange war, ist nachträglich nicht festzustellen. Heftige Gallensteinkolik- und Perforationsschmerz können leicht miteinander verwechselt werden. Selbst Darmsperre und Bauchfellreizung begleiten oft einen einfachen Gallensteinanfall.

Die Tatsache, daß der 67jährige Kranke vor einiger Zeit einen derartigen schweren Anfall überstanden hatte, ließ es als erstrebenswert erscheinen, auch diesmal einen ähnlichen günstigen. Ausgang, möglichst ohne Operation, zu erreichen. Jedenfalls erschien uns der operative Eingriff unmittelbar nach Aufnahme des Patienten nicht unbèdingt erforderlich.

Erst beim Eintritt der schweren eindeutigen Symptome von Perforation und beginnender Peritonitis wurde sofort operiert.

Der Verlauf der Erkrankung ist ein Beispiel dafür, wie schwierig die Diagnose und wie noch viel schwieriger die Indikationsstellung zum Eingriffe bei solchen Krankheitszuständen sein kann. Die allgemein ärztlichen Erwägungen $\mathrm{Bumms}$ und der dringende Wunsch, ein so wertvolles Leben unter allen Umständen zu erhalten, brachten Internisten und Chirurgen in eine sehr schwere Lage. Es liegt eine große Tragik darin, daß dieser Meister der Bauchchirurgie gerade einer heimtückischen Peritonitis nach Gallenblasendurchbruch zum Opfer fallen mußte.

München, 1. II. 1925.

F. v. Müller, Jehn. 